\title{
TEACHING MATHEMATICAL CONCEPTS TO PRIMARY STUDENTS IN AN INTEGRATED CLASSROOM
}

\author{
KWOK ,YUK-YIN ${ }^{1}$, MAK, KAI-LONG ${ }^{2} \&$ KWAN, CHUN-KIT ${ }^{3}$ \\ ${ }^{l}$ Division of Languages and Communication, College of Professional and Continuing Education, The Hong Kong Polytechnic \\ University, Hung Hom, Hong Kong \\ ${ }^{2 \& 3}$ Division of Science, Engineering and Health Studies, College of Professional and Continuing Education, The Hong Kong
} Polytechnic University, Hung Hom, Hong Kong

\begin{abstract}
There is an increasing trend for students diagnosed with Special Education Needs (SEN) admitted in mainstream primary or secondary schools over the last decade in Hong Kong. Even though the government has provided support to schools and teachers, teachers still have concerns about teaching in integrated classrooms. This study aims at identifying a teaching strategy that is applicable in an integrated classroom, where both groups of primary students, including both general students and those with SEN, can learn together and successfully grasp the basic mathematics concepts taught in a class. The 60 participating students were invited to attend a 45-minute mathematics lesson, in which an interactive approach was adopted to teach students the concepts of calculating the angles of a parallelogram. After the lesson, they were required to sit for a post-experiment test. They were also invited to offer their feedback voluntarily in the semi-structured interviews. A statistical analysis of covariance, ANCOVA, was carried out, and no significant differences were found between the performance of general students and their counterparts with SEN in the post-experiment test. Also, students enjoyed learning together in an inclusive learning environment and reflected that their learning experience could be enhanced.

KEYWORDS: Teaching Mathematical Concepts, Integrated Classroom
\end{abstract}

Received: Apr 03, 2020; Accepted: Apr 23, 2020; Published: May 16, 2020; Paper Id.: IJESRJUN202002

\section{INTRODUCTION}

\section{Integrated Education in Hong Kong}

Since 1997, the Hong Kong SAR government has promoted the Whole School Approach (WSA) to Integrated Education in Hong Kong (Education Bureau, 2014). Under this approach, students who need mild education support can be admitted to mainstream schools, where they can receive education together with their peers and benefit from an inclusive school culture.

The trend for students diagnosed with Special Education Needs (SEN) admitted in mainstream primary or secondary schools in Hong Kong have been increasing over the last decade. In the 2012-13 school year, there were 16,810 students with SEN studying in mainstream primary schools, accounted for $6.5 \%$ of the total number of primary students. The number increased to 22,980 in $2017-18$, accounted for $7.8 \%$ of the total number of primary students in that school year (Audit Commission, 2018; Legislative Council Secretariat, 2019). It is noteworthy that there were about $85 \%$ of students with SEN studying in mainstream primary or secondary schools in the 2017-18 schools year, and among them, 20\% were identified as Attention Deficit/Hyperactivity Disorder cases (AD/HD) (Research Office, Legislative Council Secretariat, 2019). 
Although more SEN students have been admitted into mainstream schools, full implementation of integrated education in Hong Kong remains controversial (Wong-Ratcliff \& Ho, 2011). On the one hand, this approach provides equal education opportunities to students. In the past years, there were examples that students with SEN could excel in mainstream schools and have remarkable academic achievements (Audit Commission, 2018). On the other hand, many teachers felt doubtful if students with SEN should be taught in an inclusive classroom environment (Wong-Ratcliff \& Ho, 2011). Even though the government has provided support to schools and students in different aspects, enhancement is wanting in many areas for successful implementation of integrated education (Chao, Forlin\& Ho, 2016).

One of the most significant areas that needs enhancement is the teaching strategies which teachers adopted in classroom as there are different types of SEN required by students. In Hong Kong, the Education Bureau classified nine types of SEN, including Specific Learning Difficulties (SpLD), Attention Deficit/Hyperactivity Disorder cases (AD/HD), Autism Spectrum Disorders (ASD), Speech and Language Impairment (SLI), Intellectual Disability (ID), Hearing Impairment (HI), Physical Disability (PD), Visual Impairment (VI), and Mental Illness (MI). Observing the different SEN among students, the Education Bureau suggests that "teachers can no longer adopt one single teaching approach for all students, nor can they expect all students to attain the same academic standard"(Education Bureau, 2014, p.1). Although the government has provided training and support, Hong Kong teachers will need effective teaching approaches to cater for the various education needs of students in an integrated classroom.

\section{Teaching Mathematics to Primary Students with Special Education Needs}

Different instructional skills are required for teaching different subjects. Teaching mathematics can be a challenging task for teachers because most students may not really understand the important concepts behind when working on maths exercises in their textbooks. Kellner and Attorps (2015) stated that primary students find mathematics difficult because they usually perceive mathematics as a school subject. However, mathematics is important not only in school settings, but also in students' everyday life (Mercer \& Miller, 1992). Therefore, Kellner and Attorps (2015) argue that it is important to develop students' understanding of maths concepts through effective teaching instructions and strategies.

Mercer and Miller (1992) point out that students with learning problems would have problems with their maths learning as these students' learning difficulties in mathematics subjects "are often compounded by ineffective instruction" (p.20). Likewise, Storeygard (2012) in her article argues that "too often mathematics instruction for students with disabilities is confined to rote skills" (p.48). Instead of learning mathematics by rote, in their study, Liu and Xin (2017) emphasise the importance of communicative activities in teaching, which can effectively scaffold the knowledge of both general students and those with SEN. However, there are not many examples demonstrating what strategies are suitable for teaching mathematics in a real integrated classroom (Storeygard, 2012).

\section{OBJECTIVES OF THE CURRENT STUDY}

This study aims at identifying a teaching strategy that is applicable in an integrated classroom, where both groups of primary students, including both general students and those with SEN, can learn together and successfully grasp the basic mathematics concepts taught in the limited class time. 


\section{PARTICIPANTS}

60 primary six students (age 11-13) from a primary school in Hong Kong participated in this study. Of those 60 students, 30 of them have been identified with AD/HD. As mentioned above, there are different types of SEN. Only students with AD/HD were included in this study because AD/HD is a major type of SEN among the students with SEN in Hong Kong. It ranked the second highest in five academic years between 2012/13 to 2016/17. Furthermore, the number of students with AD/HD increased drastically in these five years, from 4,780 to 9,440 (+ 97\%) (Audit Commission, 2018). More importantly, students with AD/HD usually have the characteristics that are not favourable to learning mathematics. For example, they would find it difficult to stay focused on a task. In particular, it is hard for them to work on organised activities. In addition, they would make careless mistakes easily (Audit Commission, 2018).

\section{METHODOLOGY}

The study was taken place in a local primary school in Hong Kong. Students were invited to attend a 45-minute mathematics lesson (N.B.: 45 minutes is the normal duration of a mathematics lesson in Hong Kong primary schools.) during the post-examination period in June 2019. The 60 participating students, regardless their education needs, were randomly divided into two classes by their school teachers. Each class had approximately 30 students. The two classes were taught by one of the researchers of this study. He conducted both lessons with the assistance of three helpers. The helpers helped distribute the teaching material to students and provided assistance to students when they needed help.

\section{Research Design}

During the 45-minute lesson, an interactive teaching and learning approach was adopted. The researcher used a set of material which was tailored for this study to teach students the characteristics of a parallelogram so as to let them understand the concept of calculating the angles of a parallelogram by making use of the unique properties of it. The set of material included two sets of graphs: (1) two sets of parallel lines forming a parallelogram. The identical graphs were printed on a transparency and a piece of white paper, and (2) a transparency with a straight dotted line printed on it.

First, students were introduced the concept of alternate and corresponding angles in two parallel lines. They were told to use the first set of material and put the transparency on the white paper to ensure all the lines overlapped. Then, they were asked to move the transparency along the horizontal parallel lines and shade the angels that were in the same degree in the same colour. Afterwards, they were told to move the transparency along the white paper vertically and rotate the transparency to find out all the similar angles. Eventually, students discovered that the 16 angles were shaded in two different colours only. In other words, the 16 angles could be grouped in 2 groups (as shown in figure 1).

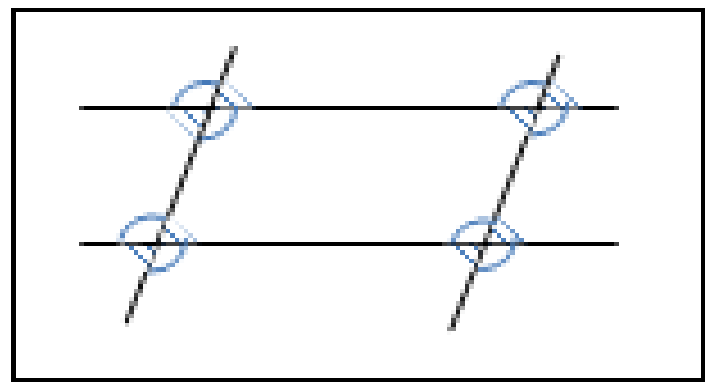

Figure 1: Alternate and Corresponding Angles in a Parallelogram. 
Next, students were introduced the concept of similar triangles by using the second set of material. They were told to put the transparency on the parallelogram, cutting the two horizontal parallel lines and form two similar triangles (as shown in figure 2).

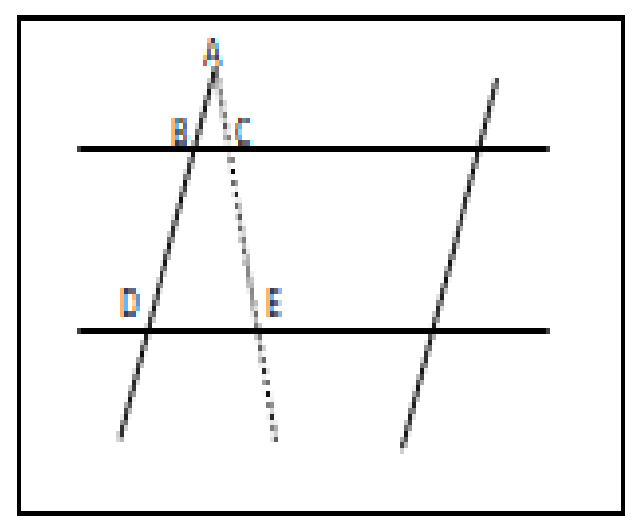

Figure 2: Forming Similar Triangles.

When students were asked about the relationship between $\square \mathrm{ABC}$ and $\square \mathrm{ADE}$, they were hinted that they could apply the concept of alternate and corresponding angles in two parallel lines. Most of the students could figure out that $\angle \mathrm{B}$ and $\angle \mathrm{D}$ were equal, and therefore, $\angle \mathrm{C}$ should equal to $\angle \mathrm{E}$, given that the interior angles of a triangle always sum to 180 degrees. Students could then work out that $\square$ ABC and $\square$ ADE were two similar triangles because their three interior angles shared the same properties.

\section{DATA COLLECTION}

In this study, both quantitative and qualitative data were collected to investigate the effectiveness of the proposed teaching strategy. First, all participating students were required to sit for a post-test after the lesson. Their answers to the test questions were marked and computed for checking how well they could handle the concepts taught in the lesson. After the lesson, participating students were invited to provide oral or written feedback and comments on the teaching approach to their class teachers.

\section{Post-experiment Test}

After the lesson, all 60 participating students were required to take part in a short written test. In the test, there were eight short questions asking students to identify corresponding and alternative angles as well as similar triangles in a given graph. A statistical analysis of covariance, ANCOVA, was carried out to identify if there were significant differences between the test results of general students and those of students with SEN.

\section{Post-experiment Interviews}

Aiming to solicit students' views on the proposed teaching strategy, participating students were invited to give feedback and comments on the proposed teaching approach to their class teachers. Because the students were primary schools students, and some of them were students with SEN, the school personnel suggested that it would be more appropriate to collect the feedback through class teachers since such arrangement would help avoid uncomfortable feelings of students. To ensure the consistency of data collection procedure, the researcher had prepared an interview guide for the class teachers and gave them a briefing before the interviews. Each participating student was asked the same set of pre- 
determined questions, and follow-up questions would be asked based on students' responses. Fifteen students participated in the individual, semi-structured interviews.

\section{FINDINGS AND ANALYSIS}

A set of tailored teaching material related to geometry was successfully developed based on the need of students with SEN. The material was designed for enhancing the teaching and learning of an integrated classroom.

\section{Analysis of Covariance}

A statistical analysis of covariance, ANCOVA, was carried out to identify if there were significant differences between the performance of general students and their counterparts with SEN in the post-experiment test.

ANCOVA is a general linear model which blends ANOVA and regression. ANCOVA evaluates whether the population means of a dependent variable are equal across levels of a categorical independent variable, while statistically control the effects of other continuous variables that are not of primary interest, known as covariates (such as educational background among students in this study). Therefore, when ANCOVA is performed, the means of the dependent variable are adjusted to what they would be if all groups are supposed to be equal on the covariates. In this study, Principal Component Analysis (PCA) was conducted to minimise the effect of students' previous academic performance in mathematics subjects. PCA was used on three interested confounding factors: (a) students' maths subject result in primary 6,(b) students' maths subject result in primary 5, and (c) students' maths subject result in primary 4.The results of PCA were applied to defining the covariate of ANCOVA.

PCA was applied to the data set of this study, and the eigen values and percentage of variance represented by corresponding components are shown in Table 1. The result showed that two components had eigen values that were $>1$, so it was suitable to select these three components as the principal factors in the data set of this study. Varimax with Kaiser normalisation was applied for rotation methods of extracting the principal components. The corresponding components are shown in table 2.

Table 1: Eigenvalues and Percentage of Variance Represented by Corresponding Components

\begin{tabular}{|c|c|c|}
\hline Component & Eigenvalues & \% of Variance \\
\hline 1 & 2.928 & 61.80 \\
\hline 2 & 1.382 & 29.13 \\
\hline 3 & 0.429 & 9.07 \\
\hline
\end{tabular}

Table 2: Result of Principal Components Analysis (PCA)

\begin{tabular}{|l|c|c|}
\hline & \multicolumn{2}{|c|}{ Component } \\
\hline & $\mathbf{1}$ & $\mathbf{2}$ \\
\hline Maths subject result in P6 & $0.834^{*}$ & 0.231 \\
\hline Maths subject result in P5 & -0.003 & $0.759^{*}$ \\
\hline Maths subject result in P4 & 0.101 & 0.108 \\
\hline
\end{tabular}

After Varimax rotation, two components were extracted by the PCA. The first component had two significant coefficients: students' maths subject result in primary 6 , which could represent $61.8 \%$ of the overall variation. The second component had one significant coefficient, which was the students' maths subject result in primary 5. The second component represented $29.13 \%$ of the overall variation. 
ANCOVA was used to identify if there were significant differences among different factors. In order to confirm the equal variance assumption of ANCOVA, Levene Statistical Test was performed prior to ANCOVA. A value of $>0.05$ for significant value reflects the equal variance assumption is valid. Significant differences were not identified between the group of general students and the group of students with SEN. The result is shown in table 3.

Table 3: Levene Statistical Test and ANCOVA Result of Different Factors

\begin{tabular}{|l|l|c|c|}
\hline \multicolumn{1}{|c|}{ Dependent Variable } & \multicolumn{1}{|c|}{ Factor } & $\begin{array}{c}\text { Levene Statistical Test } \\
\text { (Significant Value) }\end{array}$ & $\begin{array}{c}\text { ANCOVA } \\
\text { (Significant Value) }\end{array}$ \\
\hline $\begin{array}{l}\text { result of post- } \\
\text { experiment test }\end{array}$ & $\begin{array}{l}\text { general students } \\
\text { and students with } \\
\text { SEN }\end{array}$ & 0.891 & 0.791 \\
\hline *Coefficient is significant at the 0.05 level.
\end{tabular}

According to the results, there were no significant differences between the general students and students with SEN in terms of the post-experiment test result.

\section{Feedback from Students}

All fifteen students had positive feedback on the proposed teaching strategy. More than $90 \%$ of them suggested that the teaching strategy could better facilitate their learning. In addition, the students from both groups could make good use of the material and complete the learning activity satisfactorily.

Student A (with SEN): I liked the activity. I could concentrate on the task and complete it easily by following theinstructions.*

Student B (with SEN): I could concentrate on the task. I raised questions when I had questions about the given task.*

Student C (general): The teaching was lively. The activity was fun. It could arouse my learning interest.*

(*The interviews were conducted in Cantonese. Students' feedback was transcribed and translated into English.)

From the feedback of students, it could be seen that students enjoyed the lesson in general, and interesting learning activities could help them stay focused when clear instructions and appropriate learning aids were provided to them.

\section{DISCUSSION}

The proposed teaching strategy was effectively implemented in an integrated classroom, where both groups of primary students, including both general students and those with SEN could learn together and successfully grasp the mathematics concepts taught in the limited class time. With the tailored materials, the teacher provided an inclusive learning environment to students, where their learning experience could be enhanced.

In most classrooms, teachers and students usually rely on textbooks as a major teaching and learning resource (Helmane, 2016; Kellner and Attorps, 2015). Rather than simply learning from textbooks and working on review exercises repeatedly, the teaching strategy adopted in this study put an emphasis on learning through an interactive activity. It is shown that the design of teaching materials used in this study effectively aided students' learning. Students were actively involved in the teaching activity, in which they could acquire the maths knowledge through their own experience. The findings of this study echoed the suggestion of Storeygard (2012) that if teachers could adopt different teaching approaches and use appropriate teaching aids, it could help "focus students and reduces the reliance on auditory processing, an area 
that is often difficult for students with attention problems" (p.49).

Moreover, getting students, including those with SEN, involved in class activities is of considerable importance in an integrated classroom. Liu and Xin (2017) mention that students with learning difficulties might have limited opportunities to get involved in class activities, so they argue that compared to passive learning, teachers could provide more support and opportunities to engage students in class activities in order to enhance students learning experience. In this study, students were taught the concepts of alternate and corresponding angles in two parallel lines, and the concept of similar triangles through an activity. The results of the post-experiment test showed that both groups of the participating students could grasp the concepts taught and applied them appropriately in solving the related geometry problems. Most importantly, the results did not show significant differences between the two groups of students. It reflects that the activity used in this study worked well in an integrated classroom.

\section{CONCLUSION}

The findings of the current study revealed that appropriate teaching strategies are needed for a true integrated classroom, where both SEN students and the general students can benefit from an inclusive school culture. With the aid of appropriate teaching and learning strategies, SEN students could learn equally well as general students.

This study showed that interactive teaching strategies would be a workable and manageable choice in an integrated classroom. With the assistance of technology, more interactive and innovative teaching strategies could be developed for the integrated classroom environment in the future so as to enrich students' learning experience. However, careful planning of teaching and learning strategies, especially those prepared for inclusive classrooms, is needed as students' education needs always vary. In addition, various interactive teaching and learning approaches should be introduced for subjects of different academic disciplines.

\section{REFERENCES}

1. Audit Commission, HKSAR. (2018). Education Bureau - Integrated education. Retrieved from https://www.aud.gov.hk/pdf_e/e70ch03.pdf

2. Chao, C. N. G., Forlin, C., \& Ho, F. C. (2016). Improving teaching self-efficacy for teachers in inclusive classrooms in Hong Kong. International Journal of Inclusive Education, 20(11), 1142-1154.

3. Education Bureau, HKSAR. (2014). Operation guide on the whole school approach to integrated education. Retrieved from https://www.edb.gov.hk/attachment/en/edu-system/special/support/wsa/ie\%20guide_en.pdf

4. Helmane, I. (2016). Emotions of primary school pupils in mathematics lessons. SignumTemporis, 8(1), 22-29.

5. Kellner, E., \&Attorps, I. (2015). Primary school teachers' concerns and needs in biology and mathematics teaching. Nordina, 11(3), 282-292.

6. Liu, J., \& Xin, Y. P. (2017). The effect of eliciting repair of mathematics explanations of students with learning disabilities. Learning Disability Quarterly, 40(3), 132-145.

7. Mercer, C. D., \& Miller, S. P. (1992). Teaching students with learning problems in math to acquire, understand, and apply basic math facts. Remedial and Special Education, 13(3), 19-35.

8. Research Office, Legislative Council Secretariat, HKSAR. (2019). Special education needs. Retrieved from https://www.legco.gov.hk/research-publications/english/1819issh22-special-educational-needs-20190219-e.pdf 
9. Storeygard, J. (2012, September). My child "can": Going beyond the ADHD label to help students learn mathematics. EP Magazine, 48-50.

10. Wong-Ratcliff, M., \& Ho, K. K. (2011). Can integrated education meet the needs of students with SEN? New Horizons in Education, 59(2), 101-115. 